\title{
Esophageal Motor Abnormalities in Scleroderma and Related Diseases
}

\author{
Thomas A. Saladin, M.D.,* Arthur B. French, M.D., \\ Curis J. D. Zarafonetis, M.D., and H. Marvin Pollard, M.D.
}

$\mathrm{E}$ SOPHAGEAL symptoms are common and often troublesome in patients with scleroderma. ${ }^{1-11}$ Although motor abnormalities of the esophagus can often be demonstrated by radiologic studies $2,3,6-14$ or by intra-esophageal pressure recordings ${ }^{15-20}$ in these patients, there is poor correlation between radiologic abnormalities and symptoms. ${ }^{14}$ The precise relationships between abnormalities of intra-esophageal pressure recordings and symptoms or radiologic abnormalities have not been clearly defined. The present study attempts to demonstrate the relationship between esophageal symptoms and abnormalities of intra-esophageal pressure recordings in patients with scleroderma and other collagen diseases. The study shows that evidence of abnormal esophageal motor activity is often found in patients with scleroderma without esophageal symptoms. Such evidence is also found in patients with Raynaud's phenomenon and no other evidence of scleroderma, and in patients with other collagen disease such as dermatomyositis. The incidence of abnormal intra-esophageal pressure recordings does not relate to the presence or absence of significant esophageal symptoms.

The effect of acetyl- $\beta$-methyl-choline was studied to determine if denervation of the esophagus accompanies esophageal motor abnormalities in scleroderma and to explore the observation of Lorber and Zarafonetis ${ }^{14}$ that emptying of the esophagus was improved by administering a cholinergic drug to patients with scleroderma and esophageal involvement. If denervation were present, Cannon's law would predict hypersensitivity to mecholyl, as is seen in achalasia. In support of previous reports, no such effect was observed. Aperistaltic contractions did not become peristaltic and the amplitude of the primary waves did not change.

From the Department of Internal Medicine (Gastroenterology Section and Simpson Memorial Institute), The University of Michigan Medical School, and the Clinical Research Unit of the University of Michigan Hospital, Ann Arbor, Mich.

Supported by Grant FR-42 from the General Clinical Research Centers Branch, Division of Research Facilities and Resources, The National Institutes of Health, and equipment provided in part from its General Research Support Grant to The University of Michigan Medical School.

* Advanced Clinical Fellow of The American Cancer Society (ACF Grants 64A and 64B). 


\section{MATERIALS AND METHODS}

Esophageal motor activity, as reflected by intra-esophageal pressure changes, was recorded in 53 patients with known scleroderma. For comparison it was also measured in 29 patients with other "collagen" diseases or with Raynaud's phenomenon alone. The technic was similar to that used by Code. 10, 21. 22 Three polyethylene tubes $(0.85 \mathrm{~mm}$. internal diameter $)$ were assembled with a $1-\mathrm{cm}$. $\times 0.5-\mathrm{cm}$. balloon at the bottom of the first tube, a side opening in the second tube $5 \mathrm{~cm}$. above the balloon, and another side opening in the third tube 10 $\mathrm{cm}$. above the balloon. The water-filled tubes were connected to Model $267 \mathrm{~B}^{*}$ strain gauge pressure transducers. Air was flushed from the system at the beginning of an experiment and secretions were cleared from the side openings by periodic injection of small amounts of water via a three-way valve. Respiration was monitored by a belt pneumograph; in most cases, a myogram from the accessory muscles of deglutition signalled the onset of swallowing. Results were recorded by a Model $350 *$ 8-channel system with Model $350-3000$ B* carrier preamplifiers.

The cardio-esophageal junction was studied first. The tubes were swallowed until the balloon and both side openings were within the stomach. The assembly was then withdrawn in $0.5-$ to $1-\mathrm{cm}$. increments until the terminal balloon passed the point of respiratory reversal. The swallowing mechanism was studied next. The balloon was again placed in the stomach and withdrawal into the esophagus was repeated until the upper esophageal sphincter and pharyngeal swallowing waves were recorded on one or more channels. The patient was instructed to swallow while the tube rested at each level of the esophagus. Sometimes the effect of swallowing water was also observed. The "Mecholyl $\nmid$ response" was measured last. The tubes were swallowed again until the balloon lay in the sphincter and the open tips were in the lower esophagus. Sufficient methacholine $(6.0-7.5 \mathrm{mg}$.) to cause muscarinic effects was given subcutaneously and recordings were obtained during serial withdrawal.

\section{SUBJECTS}

The patients were divided into two groups. Group 1 consisted of 53 patients with scleroderma; Group 2 consisted of 29 patients with other collagen diseases or Raynaud's phenomenon.

Between July 1963 and March 1965, 76 patients with scleroderma were seen at this medical center. For this study 53 were available and represent a reasonably unbiased sample. Two patients showed little or no skin involvement, but the diagnosis of scleroderma was clearly established in all cases. Several physicians, usually a dermatologist and a rheumatologist as well as

* Sanborn Division, Hewlett Packard Co., Waltham, Mass.

† Merck \& Co., Inc., West Point, Pa. 


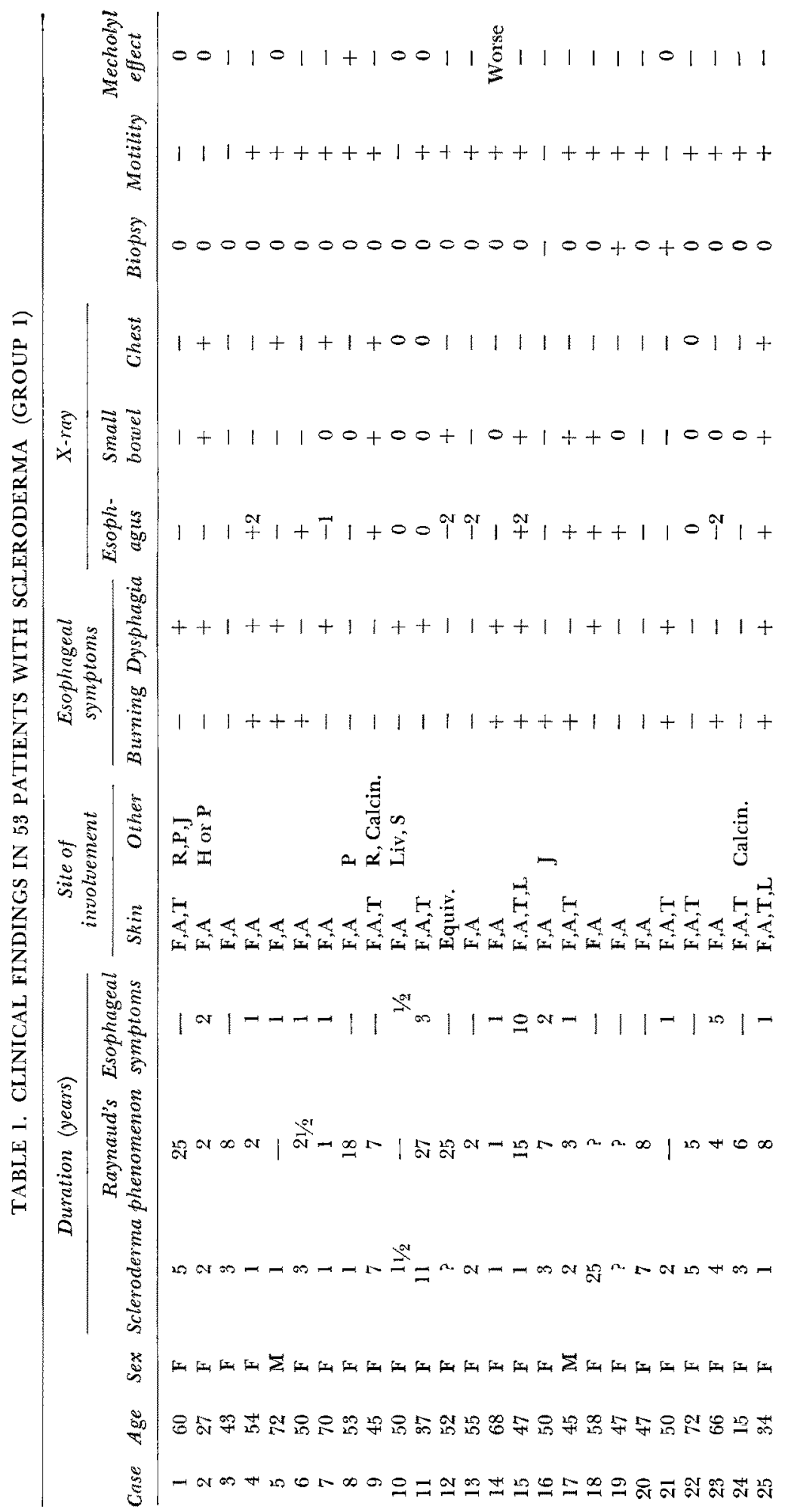




$$
\begin{aligned}
& 10_{0}^{0} 1111011001001111010110001 \\
& +1+t+t+t+1+1+t+t+1+t+t+1+t \\
& 00000+0+00++0000000+t+01+t+0
\end{aligned}
$$

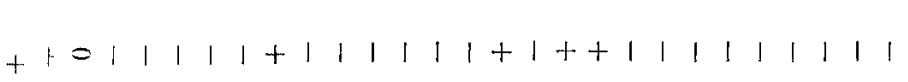

$$
\begin{aligned}
& 1100+010100110+0100101111101 \\
& +10 T+0+0+1+111++1++1+++\stackrel{o r}{+} 1 \stackrel{o r}{+}+ \\
& 1+1++1+1++1++1|1+1| 1++1+111+ \\
& 1+1+1+1+1+11+111+111111+1111 \\
& \text { a }
\end{aligned}
$$

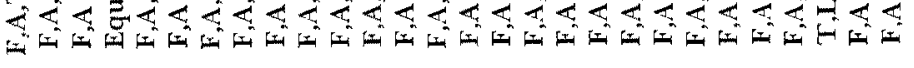

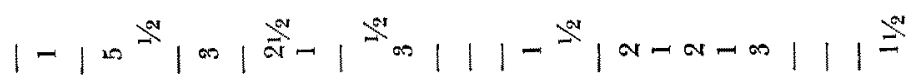

$$
\begin{aligned}
& \text { \& }
\end{aligned}
$$

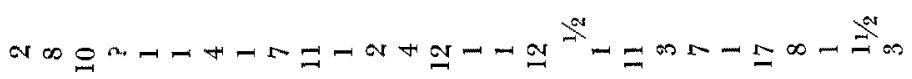

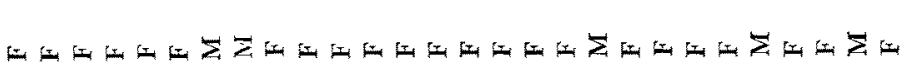

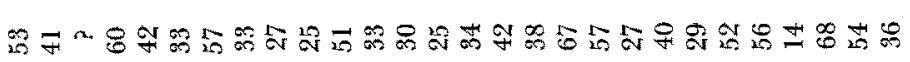

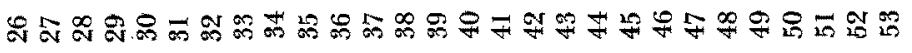

$$
\begin{aligned}
& \text { 竞畜 } \\
& \text { î }
\end{aligned}
$$

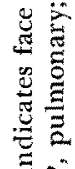

$$
\begin{aligned}
& \text { | } \\
& \text { 要 }
\end{aligned}
$$

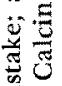

$$
\begin{aligned}
& \text { 范 } \\
& \text { 常 }
\end{aligned}
$$

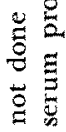

$$
\begin{aligned}
& 0 \text { ثิ }
\end{aligned}
$$

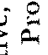

$$
\begin{aligned}
& \text { 范 } \\
& \text { 突高 } \\
& \text { है. }
\end{aligned}
$$


some of the authors, saw each patient. Some clinical details of the 53 patients (Group 1) are listed in Table 1.

Group 2 consisted of 13 patients with Raynaud's phenomenon, 7 with miscellaneous collagen diseases, 6 with disseminated lupus, 2 with dermatomyositis, and 1 believed to have scleredema. Of the 13 with Raynaud's phenomenon, 4 had no additional symptoms; 1 had cryoglobulins, 1 diarrhea, 3 lupus features, 3 possible but not clearly defined scleroderma, and 1 retroperitoneal fibrosis. The 7 with miscellaneous collagen diseases consisted of 1 with diffuse interstitial fibrosis, 1 with polymyositis, 1 with Sjogren's syndrome, 1 with rheumatoid arthritis, and 3 with unclassified arthritis.

\section{RESULTS}

Of the 53 patients with scleroderma (Group 1), 42 showed significant abnormalities of the pressure response in the esophagus during deglutition. In 27 patients contractions were absent except very high in the esophagus. In 2 additional patients contractions were feeble, in one case peristaltic, in the other case aperistaltic. In 13 patients the response to swallowing was variable. Seven of these showed an occasional normal peristaltic pressure wave, but in all 13 patients most waves were both feeble and aperistaltic. These abnormalities occurred with equal frequency (about $80 \%$ ) in both symptomatic and asymptomatic patients (Fig. 1).

A measurable increase in pressure at the cardioesophageal junction was absent in 26 of the 42 patients with abnormal pressure waves and in 2 others whose response to deglutition was a normal peristaltic pressure wave. Absent cardioesophageal sphincter pressure did correlate with symptoms at the $95 \%$ confidence level (Fig. 2) . A lower esophageal sphincter was found in only $30 \%$ of patients with symptoms, in contrast to more than $60 \%$ of those without symptoms.

The motor abnormalities seen in 10 of 29 of the patients in Group 2 were similar to those in Group 1. Complete absence of contractions was seen in only 3 patients: 1 with dermatomyositis, 1 with Raynaud's phenomenon and suspected disseminated lupus erythematosus, and 1 with Raynaud's phenomenon and suspected scleroderma. In the other abnormal records there were only feeble, simultaneous waves in response to swallowing. Nine of the 10 patients in Group 2 with abnormal motor responses to swallowing showed Raynaud's phenomenon (Table 2). In the patient with dermatomyositis and absent contractions the abnormality was most prominent in the lower two-thirds of the esophagus and was identical to that seen in the patients with scleroderma.

The relationship of symptoms to motor abnormalities during deglutition and to abnormalities of the lower esophageal sphincter are shown in Fig. 1 and 2. In Group 2 patients there was little correlation with either aperistalsis or decreased sphincter pressure. 
In both Group 1 and 2 patients, intraluminal pressure studies were always abnormal when roentgen studies were abnormal (Table 3). However, normal $\mathrm{X}$-ray findings were common in patients whose intra-esophageal pressure studies were abnormal. Radiologic abnormalities included dilatation of the body of the esophagus in 3 patients, decreased peristalsis in 7 , and both abnormalities in 13. Barium remained in the esophagus as long as $2 \mathrm{hr}$. in some cases, but carefully timed studies of transit time for barium were not obtained.

Methacholine (acetyl- $\beta$-methyl-choline, Mecholyl) was given to 36 of the patients in Group 1 in whom the swallowing response was abnormal. In 33 the characteristics of the pressure tracing did not change; in 1 the tracing improved with an increase in both amplitude and orderliness of the primary wave;
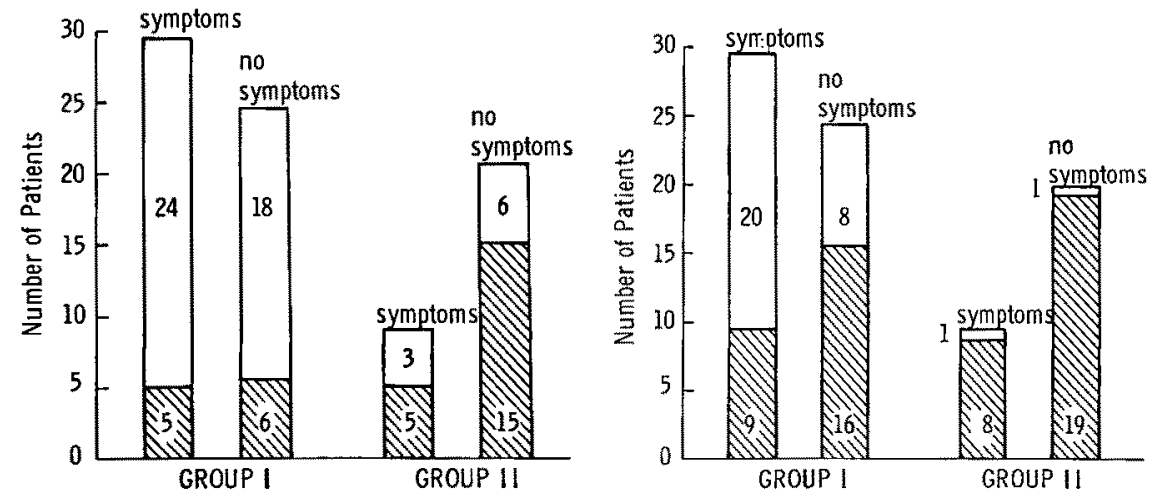

Fig. 1 (left) . Esophageal symptoms and esophageal aperistalsis. Hatched area, normal; clear area, abnormal. Group 1: $\chi^{2}=0.481 ; p=0.50$. Group 2: $\chi^{2}=0.215 ; 0.7>p>0.5$. Fig. 2 (right). Esophageal symptoms and absence of lower esophageal sphincter. Hatched area, sphincter; clear area, no sphincter. Group 1: $\chi^{2}=5.85 ; 0.02>p>0.01$. Group 2: $\chi^{2}=0.359$; $0.7>\mathrm{p}>0.5$.

TABLE 2. ESOPHAGEAL INTRALUMINAL PRESSURE RESPONSE TO DEGLUTITION IN 29 PATIENTS WITH COLLAGEN DISEASE OTHER THAN WELL-DEFINED SCLERODERMA

\begin{tabular}{|c|c|c|c|c|}
\hline \multirow[b]{2}{*}{ Diagnosis } & \multicolumn{2}{|c|}{ Patients with aperistalsis } & \multicolumn{2}{|c|}{ Patients with normal peristalsis } \\
\hline & Tolal & $\begin{array}{l}\text { With Raynaud's } \\
\text { phenom. }\end{array}$ & Total & $\begin{array}{l}\text { With Raynaud's } \\
\text { phenom. }\end{array}$ \\
\hline Raynaud's alone & 2 & 2 & 2 & 2 \\
\hline $\begin{array}{l}\text { Raynaud's with suspected } \\
\text { collagen disease }\end{array}$ & 4 & 4 & 5 & 5 \\
\hline Miscellaneous & 1 & 1 & 6 & 0 \\
\hline Lupus & 2 & 1 & 4 & 0 \\
\hline Dermatomyositis & I & 1 & 1 & 0 \\
\hline Scleroderma & 0 & 0 & 1 & 0 \\
\hline TOTAL & 10 & 9 & 19 & 7 \\
\hline
\end{tabular}


TABLE 3. ESOPHAGEAL INTRALUMINAL PRESSURE ABNORMALITIES AND X-RAY ABNORMALITIES IN GROUPS 1 AND 2

\begin{tabular}{lccccc}
\hline & \multicolumn{2}{c}{ Group 1 motility } & & \multicolumn{2}{c}{ Group 2 motility } \\
\cline { 2 - 3 } \cline { 5 - 6 } X-ray interpretation & Normal & Abnormal & & Normal & Abnormal \\
\hline Normal & 9 & $13^{*}$ & & 12 & 5 \\
Abnormal & 0 & $23 \dagger$ & & 0 & 2 \\
No X-ray & 2 & 4 & & 7 & 3 \\
Mistake in X-ray diagnosis & 0 & $2+$ & & 0 & 0 \\
\hline
\end{tabular}

*Two patients had hiatus hernia.

$\dagger$ Five patients had hiatus hernia.

${ }_{\ddagger}$ Achalasia was diagnosed for both patients.

in 2 the tracing became more abnormal, i.e., after methacholine, simultaneous waves replaced peristaltic waves. Even in these 3 cases the changes in swallowing response were minimal. The most striking response is shown in Fig. 3 and 4 . When the test was repeated 18 months later, aperistalsis, and indeed lack of contraction, were still present in the mid-esophagus. Unexpected normal peristaltic waves were found in the lower $3 \mathrm{~cm}$. of the esophagus, both before and after methacholine.

There was no change in baseline pressure, like that seen in achalasia in response to methacholine, in any of these patients. Lower esophageal sphincter pressure did not change. In 17 patients methacholine was not given because of glaucoma, pregnancy, or other reasons.

Repeated tracings in 12 patients showed minor differences in lower esophageal sphincter pressure in 3 , no difference in 8 , and increased abnormality in 1 . In the latter patient, feeble but peristaltic waves in the first tracing were replaced by nonperistaltic waves 6 months later. Swallowing water did not change the characteristics of any record from those observed after "dry swallows."

As shown in Table 1, 16 of the 29 patients with esophageal symptoms noted skin changes prior to the onset of esophageal symptoms (average, 5 years). In 6 patients the onset of skin changes and esophageal symptoms was simultaneous, while in 3 patients the esophageal symptoms appeared first. The time relationship was not clear in the other 4 cases.

In 1 patient Raynaud's phenomenon was present for 29 years before skin manifestations of scleroderma appeared. In several others, Raynaud's phenomenon appeared long before underlying scleroderma became evident.

\section{DISCUSSION}

The symptoms and radiologic diagnostic signs of esophageal involvement with scleroderma were well described years ago. In 1903 Ehrmann $^{1}$ reported the case of a patient with long-standing scleroderma who aspirated food into 


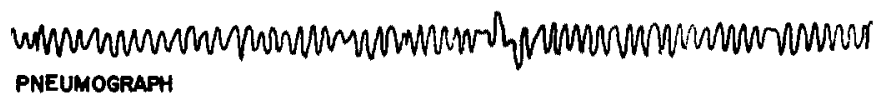

$10 \mathrm{CM}$ ABOVE BALLOON

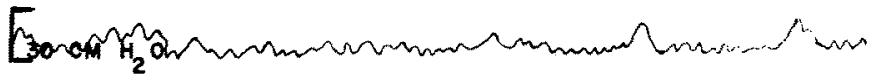

5 CM ABOVE BALLOON

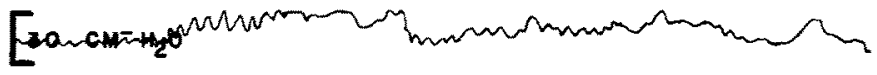

BALLOON

E0 cy Ho
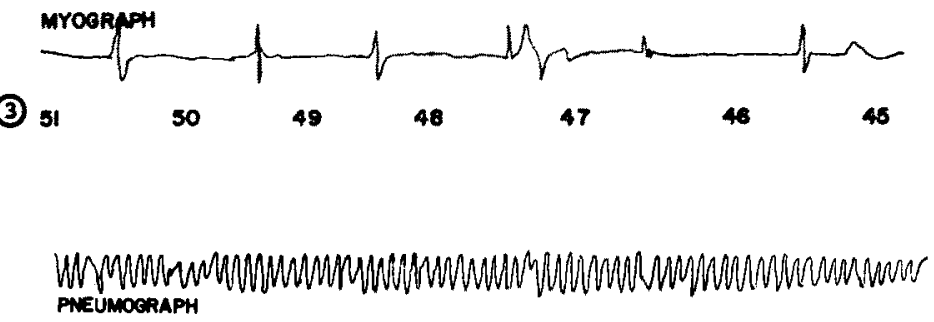

10 CM ABOVE BALLOON

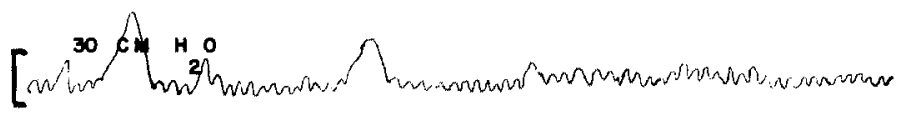

5 CM ABOVE BALLOON
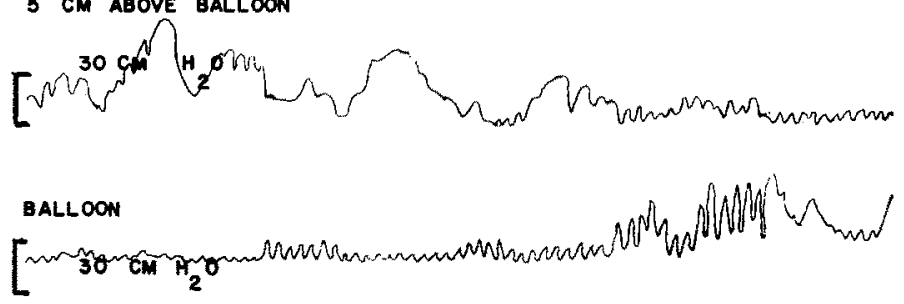

MYOGRAPH

(4) 49

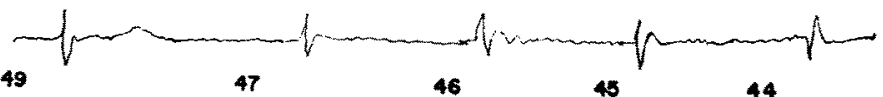

Fig. 3. Pressure tracings (rate: $1 \mathrm{~mm} / \mathrm{sec}$ ) from Patient R.W. (045636) before administration of Mecholyl, show feeble contractions, with some evidence of peristaltic progression in upper esophagus, no peristalsis in lower esophagus Fig. 4. Pressure tracings (rate: $1 \mathrm{~mm} . / \mathrm{sec}$.) from same patient after Mecholyl show stronger contractions, sometimes peristaltic. 
the respiratory tree after eating. His patient showed an upper esophageal mass. Such a mass and aspiration of food are not the usual esophageal findings in scleroderma. No autopsy was obtained when Ehrmann's patient died. Because the esophageal symptoms were very possibly due to other disease, the priority traditionally given to Ehrmann's description of the esophageal symptoms of scleroderma seems unwarranted. Schmidt ${ }^{2}$ in 1916 described a patient with the symptoms which have now become classical: dysphagia for solid foods with a sensation of food sticking high at the "jugular fossa"; X-rays showing delay at the cardioesophageal junction; the esophagus atonic, air-filled, and dilated ("Klaffen"-gaping). Helm ${ }^{3}$ in 1916 described 3 patients with scleroderma and similar radiologic abnormalities in the esophagus. Fessler and Pohl ${ }^{6}$ in 1931 reported the case of a patient with the low esophageal stricture which occasionally develops after years of esophageal involvement with scleroderma. Numerous other reports ${ }^{7-11}$ add little to these simple clinical descriptions of scleroderma of the esophagus.

Understanding of the physiologic abnormality in scleroderma of the esophagus has evolved more gradually. The manner in which motor activity of the esophagus in patients with scleroderma deviates from normal is now well defined. However, the reason for this deviation is still not clear.

Schmidt's ${ }^{2}$ use of the word "gaping" to describe the X-ray picture of the esophagus in scleroderma provided the first clue to the nature of the physiologic abnormality. Kure et al..$^{12}$ and Weissenbach et al. ${ }^{13}$ confirmed this gaping or atony and carefully documented the delayed transit which accompanies it. $\mathrm{Helm}^{3}$ showed that these X-ray findings could be seen without esophageal symptoms. In a more extensive study, Lorber and Zarafonetis ${ }^{14}$ found symptoms in 25 of 31 patients in whom esophageal peristalsis was absent by X-ray. In the present series esophageal symptoms were present in 13 of 25 patients whose X-ray studies were abnormal (Table 1).

Intra-esophageal pressure studies show a characteristic pattern. Kramer and Ingelfinger, ${ }^{15}$ recording from 20-ml. balloons, found that "propulsion of the inflated balloon down the esophagus was slow or absent" and their records "showed loss of tone and absent or markedly diminished wave pattern." The absence of the peristaltic wave pattern in the lower third of the esophagus was also seen in recordings from a small intra-esophageal differential transformer by Code et al. ${ }^{16}$ and from fine plastic tubes by Dornhorst $e$ t al. ${ }^{17}$

These changes were described in more detail by Creamer $e t$ al. ${ }^{18}$ and by Code et al. ${ }^{19}$ Intraluminal pressure recordings were characterized by poor lower esophageal sphincter pressure. The sphincter often failed to relax after deglutition. The pharyngeal and upper esophageal sphincter pressures were normal. Various abnormalities were found in the pressure response of the body of the esophagus after a dry swallow. These abnormalities included: simultaneous high pressure waves ( 1 of 9 patients); simultaneous low pressure waves ( 1 of 9 patients); complete absence of the waves (6 of 9 patients); and simultaneous 
repetitive waves ( 1 of 9 patients). We have seen all of these patterns except the last, and in addition have seen peristaltic low pressure waves.

Decreased gastroesophageal sphincter pressure was reported in 6 of 9 patients with scleroderma and esophageal symptoms by Creamer et al.18 They found that the sphincter failed to relax during swallowing in 8 of 9 patients. The close correlation found in the present study between decreased gastroesophageal sphincter pressure and dysphagia (Fig. 2) has not been reported previously.

Kramer and Ingelfinger ${ }^{23}$ reported lack of response to Mecholyl in 4 patients with scleroderma. Hightower et al. ${ }^{24}$ found no response in 1 patient. The confirmation of these findings in 36 patients makes it clear that cholinergic hypersensitivity is not characteristic of the disease.

Creamer et al. ${ }^{18}$ found abnormality of esophageal peristalsis like that found in scleroderma in both of 2 patients with Raynaud's phenomenon without scleroderma and in all 4 of 4 patients with polymyositis. Stevens et al. ${ }^{20}$ found esophageal aperistalsis in 21 of 25 patients with scleroderma, 4 of 16 patients with systemic lupus erythematosus, 3 of 21 patients with other collagen disease, and 5 of 9 patients with Raynaud's phenomenon without other disease. They did not discuss sphincter changes. As in the present series, aperistalsis was much more frequent when Raynaud's phenomenon was present. Stevens et al. ${ }^{20}$ found aperistalsis by pressure study whenever it was observed by X-ray. We found no exceptions to this pattern. However, 18 of 39 patients whose esophageal X-ray pictures were normal also showed esophageal aperistalsis in our pressure studies.

Thus, the physiologic abnormality of the esophageal scleroderma has been shown by both radiologic and manometric technics. It includes replacement of the normal strong peristaltic response to swallowing by weak, simultaneous contractions. This physiologic abnormality occurs not only in scleroderma but also in related diseases. The presence of this abnormality correlates closely with the presence of Raynaud's phenomenon. Aperistalsis is sometimes accompanied by decreased pressure in the gastroesophageal sphincter and the latter correlates better with symptoms than does esophageal aperistalsis. A postulated cause must account for these observations and also be compatible with accumulated morphologic observations.

The histologic appearance of esophageal scleroderma is well known. Many structures are involved and there are atrophic, inflammatory, and fibrotic changes. The physiologic abnormality could reasonably arise in either nervous or muscular structures, the function of which is altered by atrophic, inflammatory, or fibrotic change. Combinations are possible. However, there are objections to each explanation which has been proposed to account for the clinical and physiological observations.

Atrophy of smooth muscle and fibrosis of the esophageal wall was first described by Rake $^{25}$ in 1931. Subsequent investigators ${ }^{13,17,26,27}$ have emphasized the finding of smooth muscle atrophy and minimized the significance of fibrosis. 
Atrophy does provide a good explanation for the radiologic and manometric observation of a gaping esophagus with ineffective peristaltic contractions in response to swallowing. If it were present in all patients who show the physiologic abnormality, no further explanation would be needed. However, Treacy et al. ${ }^{27}$ found that in patients with intra-esophageal pressure measurements characteristic of scleroderma, atrophy of smooth muscle was sometimes minimal where pressure abnormalities were most striking. Stronger evidence against the etiologic importance of atrophy is the fact that atrophy of esophageal smooth muscle does not occur in other collagen diseases. Another cause for esophageal aperistalsis must be sought in these patients.

In dermatomyositis there may be myositis and atrophy of esophageal striated muscle. Stevens et al..$^{20}$ in their patient with dermatomyositis found motor abnormality in the high esophagus containing striated muscle in contrast to normal motor activity in the low esophagus where only smooth muscle is present. Creamer et al. ${ }^{18}$ found abnormality in both upper and lower esophagus in their 4 patients with dermatomyositis. In the present study aperistaltic contractions were found in the low esophagus while motor abnormality was normal in the upper esophagus. Atrophy of esophageal smooth muscle is unlikely in our patient with dermatomyositis.

Esophagitis was first mentioned by Schwarz, ${ }^{4}$ although his report does not mention esophageal symptoms or even the esophagus, except for the one word "oesophagitis." Rake ${ }^{25}$ and Weissenbach et al. ${ }^{13}$ clearly showed autopsy evidence of esophagitis. Lindsay et al. ${ }^{28}$ consistently found this evidence by biopsy in 5 patients with X-ray-demonstrated abnormalities of the esophagus. In contrast, the larger and more recent autopsy series ${ }^{26,27}$ have shown evidence of esophagitis only in a minority of cases. The gaping atonic esophagus of scleroderma is quite different from the spastic, hyperactive esophagus of classical esophagitis. Esophagitis is not a major cause of dysphagia in patients with scleroderma and esophageal symptoms. However, esophagitis is very important when "heartburn" is prominent in addition to dysphagia.

Changes in the cardioesophageal sphincter have long been discussed. Nomland ${ }^{5}$ used the word "cardiospasm" because of the delayed emptying. Rake ${ }^{25}$ also postulated that "both the esophageal and the intestinal dilatations" of his patient "were secondary to conditions of spasm occurring at the cardiac and pelvi-rectal sphincters, although the absence of any demonstrable hypertrophy shows that the spasm was of slight degree or at least intermittent and not continual over a long period." It is now recognized that many of the functional abnormalities previously ascribed to the cardioesophageal sphincter are better ascribed to inadequate peristalsis. Such is emphasized by the characteristic absence of measurable sphincter pressure in many patients with scleroderma. Although one might expect reflux and "heartburn" to result from this decrease in sphincter pressure, dysphagia and delayed transit occur. The finding of decreased sphincter pressure correlated better with symptoms than did lack of 
peristaltic swallowing waves. However, aperistaltic swallowing waves were present in all patients in whom sphincter pressure was decreased, which may simply indicate more severe involvement. The sphincter also failed to relax with swallowing in most patients in the series of Creamer et al. ${ }^{18}$ Relaxation of the sphincter probably depends on transmission of the impulse which initiates peristalsis. Failure of the sphincter to relax may imply that aperistalsis represents failure of the stimulus which initiates both peristalsis and sphincter relaxation. Atrophic smooth muscle which does not contract effectively can account for the feeble contractions which are prominent in scleroderma but not in other collagen diseases.

Absence of the ganglion cells of Auerbach's plexus, with consequent denervation of the esophagus, is apparently responsible for similar failure to transmit peristaltic waves into the smooth muscle of the esophagus in achalasia. Peristaltic activity is maintained by the myenteric reflex which is believed to pass through the ganglion cells of Auerbach's plexus as the stimulus of esophageal distention is translated into coordinated peristaltic contractions. Histologic evidence that the nerve cells in Auerbach's plexus are affected in scleroderma is contradictory and cannot be interpreted. In Rake's patient ${ }^{25}$ and in the patients of Abrams et al. ${ }^{26}$ the ganglion cells appeared normal, but in Goetz's patient $^{8}$ there was reduction of ganglion cells as well as cellular reaction around nerve fibers. One of the patients of Treacy et al. ${ }^{27}$ also showed cellular reaction about the cells of Auerbach's plexus. The functional significance of histologic changes in autonomic ganglia is not known.

Methacholine was given to patients in Group 1 for two reasons: firstly, to confirm in a large series the observation that the Mecholyl test used in the diagnosis of achalasia is indeed negative in scleroderma. This purpose was accomplished. The normal response to methacholine seems to rule out highgrade denervation similar to that in achalasia. The second purpose was to determine whether a change in motor activity as measured by intraluminal pressure studies accompanies the improved esophageal emptying observed by Lorber and Zarafonetis ${ }^{14}$ in X-ray studies. Our results indicate that improved contraction is not the reason for the improved emptying.

Histologic abnormalities in Auerbach's plexus in patients with scleroderma and the correlation between Raynaud's phenomenon and esophageal aperistalsis in most collagen diseases ${ }^{20}$ have led some to postulate that both Raynaud's phenomenon and esophageal aperistalsis are due to a neurohumeral abnormality. ${ }^{29}$ More investigation of this possibility is needed.

\section{SUMMARY}

Esophageal motor activity was measured by intra-esophageal pressure recordings in 53 patients with scleroderma and 29 patients with other collagen diseases. The purpose of the study was to determine the relationship of motor 
abnormalities to esophageal symptoms, to compare the abnormalities in scleroderma with those in other collagen diseases, and to try to increase understanding of the responsible mechanism. Methacholine was given to 36 of the 53 patients with scleroderma to confirm that the Mecholyl test is negative in scleroderma and to see whether intraluminal pressure changes accompany the resulting improvement in esophageal emptying.

Abnormalities in the intraluminal pressure response of the esophagus to deglutition were seen in $79 \%$ of the patients with scleroderma. Of those with an abnormal swallowing pattern, $62 \%$ showed diminution or absence of the lower esophageal sphincter pressure zone. Although changes in swallowing pattern did not correlate with esophageal symptoms, absence of lower esophageal sphincter pressure did. The 29 patients with other collagen diseases had similar but less severe abnormalities in the motor response to deglutition. Usually there was better preservation of the lower esophageal sphincter. Neither abnormality correlated with esophageal symptoms in this group.

The Mecholyl test was negative in patients with scleroderma. No significant change was found in the pressure studies after methacholine.

Of the 66 patients who had both X-ray and manometric studies of the esophagus, intraluminal pressure studies showed aperistalsis in all patients without peristalsis on X-ray studies as well as in 18 patients who appeared to show normal esophageal peristalsis on X-ray studies.

University Hospital Ann Arbor, Mich. 4810t

\section{REFERENCES}

1. Ehrmann, S. Ueber die Beziehung der Sklerodermie zu den autotoxischen Erythemen. Wien Med Wschr 53:1098 (and 1156), 1903.

2. Sснміт, R. Diskussion vom 11. Februar 1916. Wissenschaftliche Gesellschaft deutscher Aerzte in Boehmen: Sklerodermie mitt Dysphagie. Wien Klin Wschr 29:932, 1916 (Deut Med Wch 42:1023, 1916).

3. HeLm, F. Seltene Roentgenbilder des Oesophagus. Medizinische Klinik (Juli-Dez) : 665, 1918.

4. Schwarz, P. Sklerodermie und Roentgenkastration. Schweiz Med Wschr 7:246, 1926.

5. Nomland, R. Sclerodactyla with calcification. AMA Arch Derm 21:322, 1930.

6. Fessler, A., and PoHl, R. Stenosierender Prozess des Esophagus bei Sklerodermie. Derm Z 63:164, 1931 .

7. Ehrmann, S., and Bruenauer, S. R. Sclerodermie. In Jadassohn Handbuch der Hautund Geschlechtskrankheiten 3 Part 2). Springer, Berlin, 1931, p 806.

8. GoEtz, R. H. The pathology of progressive systemic sclerosis (generalized scleroderma) . Clin Proc 4:337, 1945.

9. O'Leary, P. A., Olsen, A. M., and Kirklin, B. R. Esophageal lesions associated with acrosclerosis and scleroderma. AMA Arch Intern Med 76:189, 1945.

10. BeERMan, H. The visceral manifestations of scleroderma, a review of the literature. Amer J Med Sci 216:458, 1948.

11. Rodnan, G. P., and Benedek, T. G. A historical account of the study of progressive sys. temic sclerosis (diffuse scleroderma). Ann Intern Med 57:305, 1962.

12. Kure, K., Yamagata, K., Tsukada, S., and Hiyoski, J. Passagestoerung des Oesophagus bei Sklerodermie und Dystrophia Musc. Progressiva. Klin Wschr 15:516, 1936. 
13. Weussendach, R. V., Steward, W. M., and Hoesli, H. Troubles fonctionnels et lesions de l'oesophage dans la sclerodermie. Ann Derm Syph (Par) 9:81 (and 198), 1938.

14. LoRber, S. H., and ZARAFonetis, C. J. D. Esophageal transport studies in scleroderma. Amer J Med Sci 245:654, 1963.

15. Kramer, P., and Ingelfinger, F. J. Motility of the human esophagus in control subjects and in patients with esophageal disorders. Amer $J$ Med 7:168, 1949.

16. Cone, C. F., Hightower, N. C., and Morlock, G. G. Motility of the alimentary canal in man. Amer J Med 13:328, 1952.

17. Dornhorst, A. C., Pierce, J. W., and Whimster, I. W. The oesophageal lesion in scleroderma. Lancet 1:698, 1954.

18. Creamer, B., Anderson, H. A., and Code, C. F. Esophageal motility in patients with scleroderma and related diseases. Gastroenterologia 86:763, 1956.

19. Cone, C. F., Creamer, B., Schlegel, J. F., Olson, A. M., Donoghue, F. E., and Andersen, H. A. An Atlas of Esophageal Motility in Health and Disease. Thomas, Springfield, IIl., 1958.

20. Stevens, M. B., Hookman, P., Siegel, C. I., Esterly, J. R., Shulman, L. E., and Hendrix, T. R. Aperistalsis of the esophagus in patients with connective tissue disorders and Raynaud's phenomenon. New Engl J Med 270:1218, 1964.

21. Fyke, F. E., Cone, C. F., and Scrnegel, J. F. The gastroesophageal sphincter in healthy human beings. Gastroenterologia 86:135, 1956.

22. Code, C. F., and Schleger, J. F. The pressure profile of the gastroesophageal sphincter in man. An improved method of detection. Proc Mayo Clin 33:406, 1958.

23. Kramer, P., and Ingelfinger, F. J. Esophageal sensitivity to Mecholyl in cardiospasm. Gastroenterology 19:242, 1951.

24. Hightower, N. C., Olsen, A., and MoERsh, H. J. A comparison of the effects of acetylbeta-methyl-choline chloride (Mecholyl) on esophageal intraluminal pressure in normal persons and patients with cardiospasm. Gastroenterology 26:592, 1954.

25. RAKE, G. On the pathology and pathogenesis of scleroderma. Bull Johns Hopkins Hosp $48: 212,1931$.

26. Abrams, H. L., Carnes, W. H., and Eaton, J. Alimentary tract in disseminated scleroderma with emphasis on small bowel. AMA Arch Intern Med 94:61, 1954.

27. Treacy, W. L., Baggenstoss, A. H., Slocumb, C. H., and Cone, C. F. Scleroderma of the esophagus. A correlation of histologic and physiologic findings. Ann Intern Med 59:351, 1969.

28. Lindsay, J. R., 'Templeton, F. E., and Rothman, S. Lesions of the esophagus in generalized progressive scleroderma. JAMA 123:745, 1943.

29. Zarafonetis, C. J. D., Lorber, S. H., and Hanson, S. M. Association of functioning carcinoid syndrome and scleroderma. I. case report. Amer J Med Sci 236:1, 1958. 